\title{
Twenty years study of solar, geomagnetic, cosmic ray activity links with monthly deaths number (n-850304)
}

\author{
Eliyahu Stoupel $^{1,2}$, Ramune Kalediene ${ }^{3}$, Jadviga Petrauskiene ${ }^{3}$, Skirmante Starkuviene ${ }^{3}$, \\ Evgeny Abramson ${ }^{4}$, Peter Israelevich ${ }^{5}$, Jaqueline Sulkes ${ }^{4}$ \\ ${ }^{1}$ Division of Cardiology, Rabin Medical Center, Petah Tiqwa, Israel; \\ ${ }^{2}$ Sackler Faculty of Medicine, Tel Aviv University, Tel Aviv, Israel; \\ ${ }^{3}$ Department of Medical Management, Lithuanian University of Health Sciences, Kaunas, Lithuania; \\ ${ }^{4}$ Management Data Center, Rabin Medical Center, Petah Tiqwa, Israel; \\ ${ }^{5}$ Department of Geophysics \& Planetary Science, Tel Aviv University, Tel Aviv, Israel. \\ Email: stoupel@inter.net.il
}

Received 8 April 2011; revised 25 April 2011; accepted 10 May 2011.

\section{ABSTRACT}

The interrelationship between human life and death at the end of the XX and beginning of the XXI centuries is the topic of this study. The aim of the study is to study links between time, Solar (SA), Geomagnetic (GMA) and Cosmic Ray (CRA) (Neutron) activity and monthly deaths distribution from all and six subgroups of death causes in years 1990-2009 for additional clarification of the role of exogenic factors in human homeostasis. Methods and patients: 850304 deaths (44657 men, 400647 woman) and 6 subgroups were studied in 240 consecutive months in the Republic of Lithuania in relation to the months of year (1 - 12), 4 indices of SA (Sunspot number and Solar Flux), 3 indices of GMA (planetary and regional for the Middle Latitudes), and CRA described by Neutron activity on the Earth's surface-remains of crushed atoms in the high space levels and measured by Imp/min. The cosmophysical data came from Space Science Institutions in the USA, Russia and Finland. Statistical analysis of the results for monthly comparison are presented. Results: It was a significant and inverse relationship of monthly deaths number for both gender with CRA and SA, less with GMA. It was a significant drop of deaths from IHD and suicides. Oncology deaths also show similarity in their timing with other groups. A strong inverse relationship was seen in monthly death number from IHD and Stroke. $(r=-0.76, p<0.0001)$, woman show more seasonality in death's distribution. Most deaths show annual rhythm with acrophase in February. Only Suicide pick appears in the summer months. Conclusion: at the beginning of the XXI century, in addition to accepted risk factors, environmental physical activity is linked to timing of death. Cosmic Ray (Neutron) activity is one of the main regulators of this relationship. Stroke related deaths are becoming a more prominent cause in the collection of cardiovascular deaths. Suicide related deaths show a drop, possibly related to a massive trend for immigration in the high risk group of the population. The precise mechanism of action of the studied physical factors needs additional studies.

Keywords: Deaths; Geomagnetic; Solar; Cosmic Ray; Neutron; Activity

\section{INTRODUCTION}

Life exists in four power fields: gravitation; electromagnetic; weak nuclear power; strong nuclear power. These factors in different ways influence life, including human homeostasis. Human life has a start-conception, and finish-death, all components of life.

The aim of this study was to explore links between levels of three physical factors related to the mentioned power fields Solar (SA), Geomagnetic (GMA) and, opposite to them, Cosmic Ray (CRA) activity and monthly distribution of human deaths number. The progress in space exploration and computerization of related physical and medical data provide now better opportunities fror such study.

\section{METHODS}

Data of the National Archive of the Republic of Lithuania for twenty years, 1990-2009 (240 consecutive months) was used. Monthly deaths distribution of 850304 persons (449657 men and 400647 women) was analyzed. Smaller groups of deaths-parts of the total group, were also studied: Ischemic Heart Disease (IHD, n-300046), 
Stroke (CVA, n-104243) and ratio between these two death groups monthly, Accidents (n-80486), Traffic Accidents (n-18532), Suicide (n-28005), deaths from malignancies (Oncologic deaths) (n-154311), Diabetes Mellitus (DM) (n-5417); an additional, artificial, group of Non Cardiovascular deaths (n-446015) was obtained, excluding from the Total deaths number deaths from IHD and CVA - two major cardiovascular killers.

All comparisons were made for total and both gender death.

The cosmophysical data (SA, GMA and CRA monthly indices) was obtained from the National Oceanic Atmospheric Administration, National Geophysical Data Center, USA, National Space Weather Prediction Center, USA, IZMIRAN Institute of the Russian Academy of Sciences, Russia, Oulu University Neutron Monitoring Station, Finland. For SA and GMA International indices of their activity were studied (1-7) - (Sunspot number, Solar flux), for GMA planetary and regional indices for the Middle Latitude (Ap., Cp., Am.) were used. For CRA Neutron activity in impulses per minute (imp/min) was used. The Neutrons are remains of atoms crushed by Cosmic Rays in the higher Space. The SA and GMA are serving as shields defending the Earth from CRA; their activities are inverse related.

\section{STATISTICS}

Pearson correlation coefficients (p) and their probabilities (r) for all physical parameters and monthly death numbers were obtained. Probabilities at $95 \%$ and higher were described as significant; probabilities of $94 \%$ 90\% were included in the Strong trends to significance category. Correlation with probability less than $90 \%$ was mentioned as Non Significant (NS). In addition, multifactor analysis was performed building prediction models for total and each pathology related deaths group, including the Intercept and significant factors for each prediction model and their probabilities.

\section{RESULTS}

First of all we checked the interrelationship between the three main studied physical factors at the 240 months of this study: SA and GMA were correlated at $\mathrm{r}=0.50, \mathrm{p}<$ 0.0001; SA and CRA (Neutron) activity were inverse related at $r=-0.85, p<0.0001$ and, the same way, GMA and CRA (Neutron) activity at $\mathrm{r}=-0.66, \mathrm{p}<0.0001$, a remembrance that SA and GMA serve as a shield for our planet from CRA.

Tables 1 and 2 present the results for total deaths and all subgroups for all fatalities and, separate, for each gender, and dynamics of IHD/CVA monthly ratio at the studied 240 months. Table 3 includes data for Oncology deaths. Table 4-for deaths related to DM. Table 5 presents results of multifactor analysis, prediction models.
Some facts emerge observing the results: yearly drop in deaths number from IHD and Suicide.

A growing role of Stroke in Cardiovascular mortality related deaths that is very significant at rise, in comparison with fatalities from IHD.

It's a sudden change in Suicide relationship with studied physical factors that were very clear and impressive from1990 until 2005, loosing significance at 2007-2008. A relative weak relationship of the studied physical factors are seen for IHD (most patients dying at home with poor verification of the event). The IHD relationship is undergoing some change in the multifactor analysis section, but demands attention in the chapter discussing the results of this study.

Between the physical factors studied the role of CRA (Neutron) activity is remarkable. The interaction of CRA with SA is following most of the observed death groups and is emerging as a principal factor of environmental forces regulating role in human homeostasis.

\section{DISCUSSION}

This long term study confirms results of a number of previous observations on links between timing of human death and environmental physical factors [8-15].

Results of this study are also reflecting the drop in IHD mortality in the last years [16].

IHD relationship with the mentioned physical factors in this study is clearer in the multifactor analysis part of the study. In this study IHD links with the physical factors are less prominent than in many studies related to Acute Myocardial Infarction (AMI), Sudden Cardiac Death (SCD), Cardiac Arrhythmia and other cardiovascular emergencies [17-27]. This can be explained by the fact that most of deaths in this group occurred at home and the verification of the cause of death was not satisfactory. This was confirmed by a group of physicians in the region were the data was collected: a great part of deaths occurred at time of alcohol intoxication; heart failure related deaths were also included in this group [28]. Better controlled studies of deaths in patients admitted to hospital and pathogenesis components of deaths from IHD (AMI, VT, VF related SCD, other forms of Cardiac Arrhythmia and Acute Cardiac Events) show highly significant relationship by timing with the level of CRA (Neutron) activity, SA and GMA [10-12,22-28].

Studies published in the XX century mostly concentrated on SA, GMA $[8,10,11,12,14]$.

CRA activity related studies came later.

It was shown that blood coagulation and inflammation indices are higher on high (active, stormy) GMA levels $[14,22,23,25]$. But extremely high (stormy) GMA days are a rare phenomena. In the last 25 years they were registered only at $3.5 \%-6.5 \%$ of days, at average, in 25 years (since 1983) $4.38 \%$ of such days yearly (400 days 


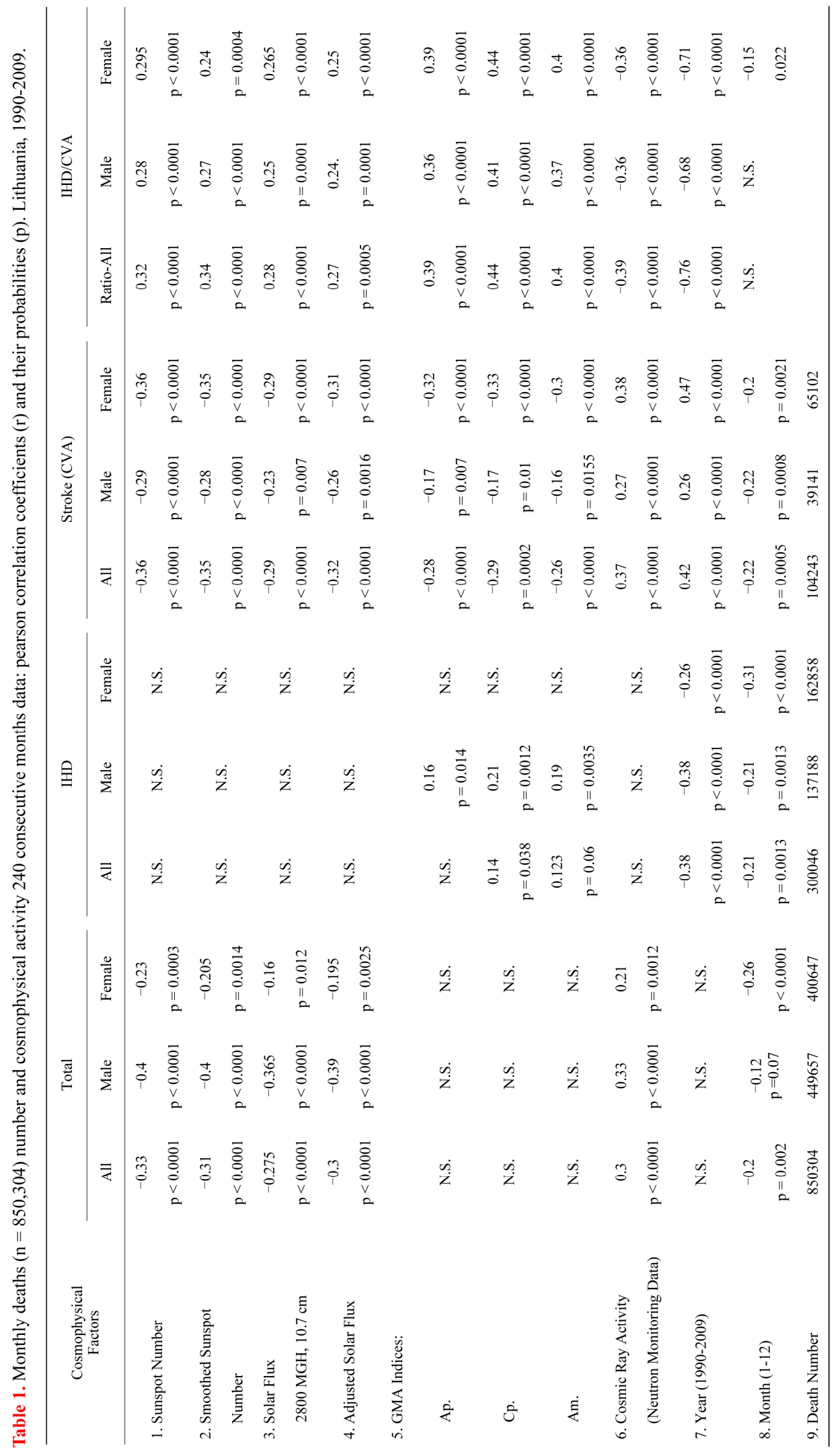




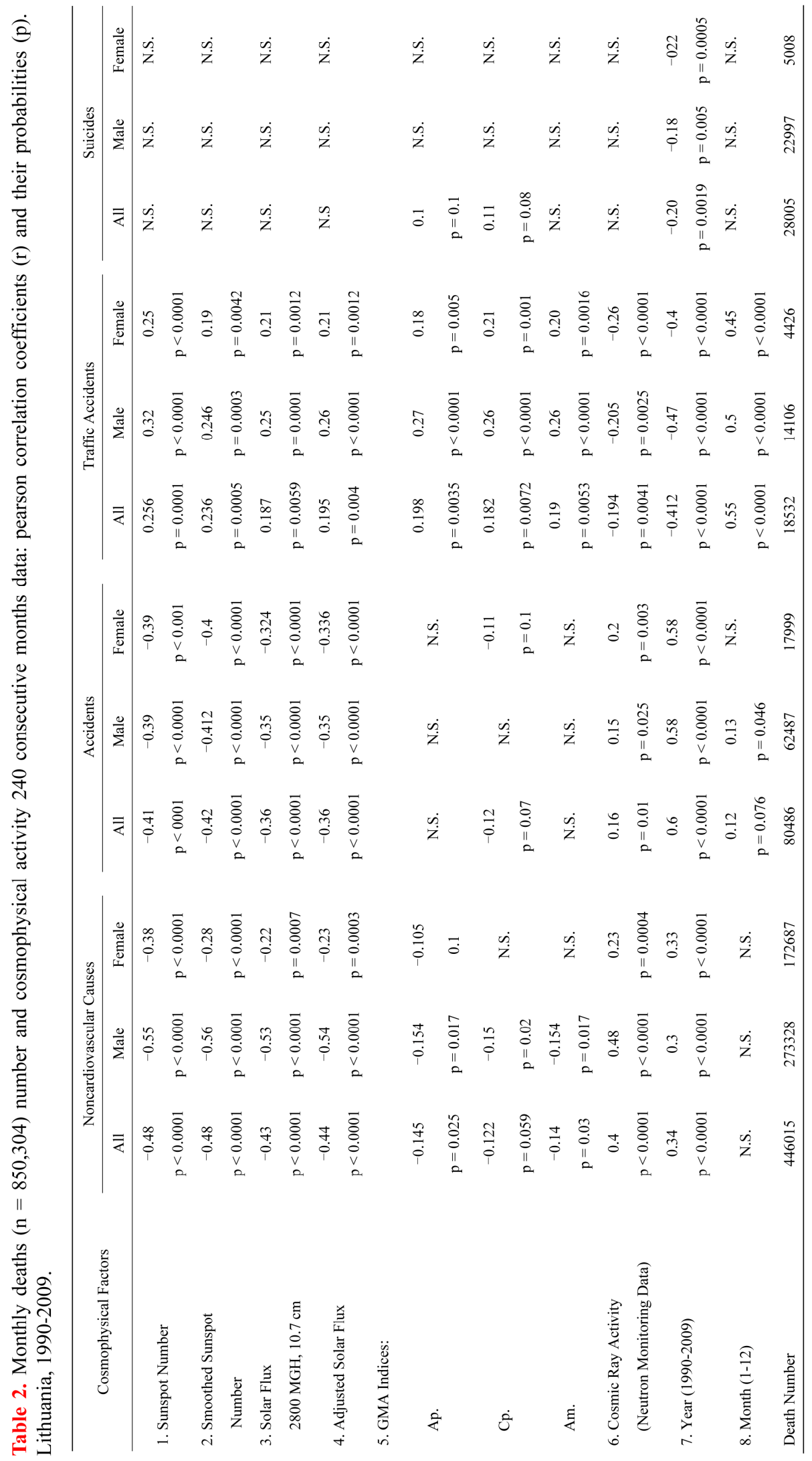


Table 3. Oncology deaths and monthly cosmophysical activity. Lithuania, 1989-2009 (252 months).

\begin{tabular}{lccc}
\hline \multicolumn{1}{c}{ Parameters } & Total & $\mathrm{M}$ & $\mathrm{F}$ \\
\hline Year & 0.67 & 0.515 & 0.62 \\
& $<0.0001$ & $<0.0001$ & $<0.0001$ \\
Month /1-12/ & 0.11 & $\mathrm{~N} . \mathrm{S}$. & 0.133 \\
& 0.08 & & 0.039 \\
Sunspot No. & -0.39 & -0.35 & -0.295 \\
& $<0.0001$ & $<0.0001$ & $<0.0001$ \\
Smoothed Sunspot No. & -0.39 & -0.35 & -0.3 \\
& $<0.0001$ & $<0.0001$ & $<0.0001$ \\
Solar Flux & -0.33 & -0.3 & -0.246 \\
& $<0.0001$ & $<0.0001$ & 0.0001 \\
Adjusted Solar Flux & -0.335 & -0.3 & -0.25 \\
GMA: & $<0.0001$ & $<0.0001$ & $<0,0001$ \\
& & & \\
Ap. & -0.29 & -0.28 & -0.19 \\
& $<0,0001$ & 0.0001 & 0.003 \\
Cp. & -0.31 & -0.29 & -0.235 \\
& $<0.0001$ & 0.0001 & 0.0002 \\
Am. & -0.29 & -0.28 & -0.205 \\
Cosmic Ray: & $<0.0001$ & 0.0001 & 0.0014 \\
Moscow & & & \\
Oulu & 0.33 & 0.32 & 0.23 \\
Deaths No. & $<0.0001$ & $<0.0001$ & 0.0029 \\
\hline & 0.34 & 0.33 & 0.23 \\
& $<0.0001$ & $<0.0001$ & 0.0023 \\
& 154311 & 86767 & 67544 \\
\hline & & &
\end{tabular}

of high active-stormy-IV ${ }^{0}$ GMA activity in 25 years).

Most of days (about 42\%) are at the weakest-Quiet GMA, accompanied by their antagonist-higher CRA (Neutron) activity [1,3].

So, despite the recognition of the "equilibrium paradigm in clinical cosmobiology" [13]—inverse action of SA, GMA and CRA on our planet and humans, most of days (in the last decades) are under low GMA and higher CRA (Neutron) activity influence.

Neutron activity, as it follows from many studies published in recent years, [18-21,28-33] is one of the leading physical powers [34-36] and is linked with the timing of human death.

The universal (not only limited to cardiovascular pathology) role of this factor can be seen in the results of timing of Oncology deaths. Here the heart standstill is only a final step of different groups of different pathologies and localizations [26]; this is also presented as a part of this study related to Oncology.

The group of Total deaths, Stroke related and other death groups also show significant connections with CRA-Neutron activity.

A very strong change is seen in the monthly IHD/ Stroke related deaths ratio since 1990. The role of Stroke is becoming more and more important with the time, and its prevention and treatment needs more and more attention by the health authorities in the coming years. Stroke development includes many pathogenesis mechanisms; some are similar to IHD natural history (the role of lipids, high blood pressure, thrombosis, embolism, atrial fibrillation etc.), but in the Stroke deaths group the correlation with the studied cosmophysical factors are much more clear [10,12,14,17,22-25]. Maybe more deaths taking place in hospital, better medical documentation and less diagnostic errors were factors making the Stroke related data much stronger related to environmental physical activity in this study.

It's remarkable the domination of woman in both (IHD, Stroke) groups, what is not specific for Western countries, but is widely seen in Eastern Europe, were men life expectancy is much shorter than woman [38] (64 for men, 74 for woman in Lithuania), and men deaths are concentrated in specific parts of pathology (accidents, traffic accidents, alcoholism and alcohol overuse related deaths, suicide etc.). [30,31,38]. This study is an additional confirmation of these studies.

We must also put attention on the group of Suicides, a cause of deaths that Lithuania was one of the leaders in the last decades [30,31]. Until year 2005 (since 1990) it was a very clear relationship of monthly Suicide related deaths number and the studied physical factors [30,31]. In the last couple of years it was.

1) A yearly drop in the number of Suicides;

2) A much weaker link with the studied physical factors;

3) All this was occurring together with massive emigration (more than $10 \%$ of the total population, first of all, the social unwell, relatively young (18-34 y. old) population-predominantly unemployed, to Western Europe (Ireland, UK, Spain and other). This population was the biggest reserve for Suicide, but not from other causes [39]. In our opinion it can explain some of the observed changes in the last couple of years in this death group. For example at 1990-2005 the yearly Suicide deaths number yearly was still significantly rising $(p=0.02)$, Correlation with SA close to $r=-05, p<0.0001$; with CRA (Neutron) activity, $r=0.31, p<0.0001$. At 19902007 not significant yearly relationship of Suicide deaths number was seen, still significant, but weaker, with SA (inverse) and CRA (Neutron) activity. In this study (1990-2009) a yearly drop in death number from Suicides $(r=-0.20, p=0.0019)$ and all long time observed relationship with the physical factors disappeared.

Considering the way of Neutron action on the pathways of Cardiac Arrhythmia, the damage of coronary artery plaque's in AMI and some cellular damage in other 
Table 4. Monthly deaths distribution from diabetes mellites (dm) links with environmental physical activity. Lithuania, 1990-2009.

\begin{tabular}{|c|c|c|c|c|}
\hline \multirow{2}{*}{ Parameter } & \multicolumn{3}{|c|}{ Deaths of Diabetes Mellites Patients } & \multirow{2}{*}{$\begin{array}{c}\text { Lithuania } \\
\text { Total Death Number }\end{array}$} \\
\hline & Male & Female & All & \\
\hline \multirow{2}{*}{ Year } & 0.31 & 0.35 & 0.44 & \multirow{2}{*}{ N.S. } \\
\hline & $\mathrm{p}<0.0001$ & $\mathrm{p}<0.0001$ & $\mathrm{p}<0.0001$ & \\
\hline \multirow{2}{*}{ Month } & \multirow{2}{*}{ N.S } & \multirow{2}{*}{ N.S. } & \multirow{2}{*}{ N.S. } & -0.19 \\
\hline & & & & $\mathrm{p}=0.0036$ \\
\hline \multirow{2}{*}{ Sunspot No. } & -0.16 & -0.15 & -0.202 & -0.35 \\
\hline & $\mathrm{p}=0.01$ & $\mathrm{p}=0.02$ & $\mathrm{p}=0.0016$ & $\mathrm{p}<0.0001$ \\
\hline \multirow{2}{*}{ Smoothed Sunspot Number } & -0.15 & -0.15 & -0.15 & -0.33 \\
\hline & $\mathrm{p}=0.01$ & $\mathrm{p}=0.02$ & $\mathrm{p}=0.02$ & $\mathrm{p}<0.0001$ \\
\hline \multirow{2}{*}{ Solar Flux 2800MGH 10.7 cm } & -0.15 & -0.12 & -0.15 & -0.29 \\
\hline & $\mathrm{p}=0.1$ & $\mathrm{p}=0.059$ & $\mathrm{p}=0.02$ & $\mathrm{p}<0.0001$ \\
\hline \multirow{2}{*}{ Adjusted Solar Flux } & -0.11 & -0.13 & -0.16 & -0.32 \\
\hline & $\mathrm{p}=0.08$ & $\mathrm{p}=0.04$ & $\mathrm{p}=0.01$ & $\mathrm{p}<0.0001$ \\
\hline \multicolumn{5}{|l|}{ GMA Indices: } \\
\hline Ap. & N.S. & N.S. & N.S. & N.S. \\
\hline Cp. & N.S. & N.S. & N.S. & N.S. \\
\hline Am. & N.S. & N.S. & N.S. & N.S. \\
\hline CRA—Neutron Activity (imp./min.) & & & & 0.32 \\
\hline Oulu & N.S. & N.S. & N.S. & $\mathrm{p}<0.0001$ \\
\hline \multirow[t]{2}{*}{ Moscow } & \multirow[t]{2}{*}{ N.S. } & \multirow[t]{2}{*}{ N.S. } & \multirow{2}{*}{ N.S. } & 0.3 \\
\hline & & & & $\mathrm{p}<0.0001$ \\
\hline \multirow[t]{2}{*}{ Death Number } & \multirow[t]{2}{*}{2152} & \multirow[t]{2}{*}{3134} & \multirow[t]{2}{*}{5417} & 850304 \\
\hline & & & & 1990-2009 \\
\hline
\end{tabular}

Table 5. Prediction of monthly deaths distribution links with environmental physical activity. Lithuania, 1990-2009.

\begin{tabular}{|c|c|c|c|c|c|c|c|}
\hline Variable & Estimate & Std. Error & p-Value & Variable & Estimate & Std. Error & p-Value \\
\hline Total & & & & \multicolumn{4}{|l|}{ Suicide } \\
\hline Intercept & 29273.0 & 8572.5 & 0.0008 & Intercept & 3057.6 & 805.9 & 0.0002 \\
\hline Year & -12.914 & 4.296 & 0.0029 & Year & -1.4 & 0.55 & 0.0008 \\
\hline Month & -21.0823 & 5.889 & 0.0004 & Sunspot No. & 0.407 & 0.17 & 0.018 \\
\hline Sunspot No. & -9.387 & 1.818 & $<0,0001$ & Solar Flux & -0.688 & 0.161 & $<0.0001$ \\
\hline Solar Flux & 6.485 & 1.74 & 0.0002 & Cosmic Ray & 0.07 & 0.0178 & $<0,0001$ \\
\hline IHD & & & & \multicolumn{4}{|c|}{ Non Cardiovascular } \\
\hline Intercept & 71735.0 & 7337.4 & $<0.0001$ & Intercept & -33714.0 & 7504.1 & $<0.0001$ \\
\hline Year & -35.39 & 3.68 & $<0.0001$ & Year & 17.83 & 3.75 & $<0.0001$ \\
\hline Month & -14.67 & 3.74 & 0.0001 & Sunspot No. & -2.13 & 0.29 & $<0.0001$ \\
\hline Sunspot No. & 5.945 & 1.002 & $<0.0001$ & Ap. & 7.62 & 2.39 & 0.0017 \\
\hline Solar Flux & 5.37 & 0.96 & $<0.0001$ & \multicolumn{4}{|c|}{ Diabetes Mellitus } \\
\hline Stroke & & & & Intercept & -833.5 & 124.3 & $<0.0001$ \\
\hline Intercept & -4947.7 & 1286.2 & 0.0002 & Year & 0.44 & 0.062 & $<0.0001$ \\
\hline Year & 2.527 & 0.641 & 0.0001 & Sunspot No. & -0.025 & 0.011 & 0.0223 \\
\hline Month & -3.738 & 0.858 & $<0.0001$ & Cosmic Ray & -0.0043 & 0.0013 & 0.0007 \\
\hline Sunspot No. & -0.89 & 0.272 & 0.0013 & & & & \\
\hline Solar Flux & 0.997 & 0.257 & 0.0001 & & & & \\
\hline Cosmic Ray & 0.061 & 0.023 & 0.01 & & & & \\
\hline \multicolumn{8}{|l|}{ Accidents } \\
\hline Intercept & -15737.0 & 1734.6 & $<0.0001$ & & & & \\
\hline Year & 8.505 & 0.868 & $<0.0001$ & & & & \\
\hline Month & 3.308 & 1.24 & 0.0086 & & & & \\
\hline Sunspot No. & -1.24 & 0.153 & $<0,0001$ & & & & \\
\hline Cosmic Ray & -0.145 & 0.017 & $<0.0001$ & & & & \\
\hline \multicolumn{8}{|c|}{ Traffic Accidents } \\
\hline Intercept & 4529.1 & 469.5 & $<0.0001$ & & & & \\
\hline Year & -2.205 & 0.239 & $<0.0001$ & & & & \\
\hline Month & 4.045 & 0.3569 & $<0.0001$ & & & & \\
\hline Cosmic Ray & -0.011 & 0.0033 & 0.0009 & & & & \\
\hline
\end{tabular}


cases, we can presume one of the Neutron acting ways is ability to invade human tissue proportional to hydrogen atoms presence there, interaction with $\mathrm{H}^{+}(41)$ (a radical that lipids and vulnerable atheroma's—plaque's are rich) and transformation of Neutrons to Protons, that attack cell nuclei and damage tissues [40,41,42].

An additional way of SA effects can be particles arriving with the Solar wind and their effects on enzymes and their function [43]. Changes in the enzyme function can also change the normal metabolism and provoke unexpected reaction of the human body, immunologic changes that are described for changes in SA and GMA $[44,45]$. This can bring to pathologic responses of the human organism to usually "normal" triggers. The way GMA is affecting blood coagulation (platelet aggregation, count, fibrinogen level etc.), inflammation (C- Reactive Protein) and many immunologic mechanisms (immunoglobulins, phospholipids) are published [14, 22,23,44,45].

The World epidemics of Diabetes Mellitus (DM) is sober represented by death number in this study. An explanation for the relative small numbers of DM related victims can be a long complications list. in the natural history of DM. They often serve as immediate cause of death-Hypertension, Renal failure, Vascular occlusions in the heart, brain, Peripheral vascular disease and diminish the number of DM related deaths.

It's also known about circannual rhythms in deaths distribution concentrating (in the Middle Latitudes of the Northern hemisphere): most IHD and CVA deaths occur in the winter (February) months, traffic accidents victims at the late autumn-start of winter and suicide acrophase in the summer (June-July) [46]. This is shown in the monthly deaths disposition (1-12) included in this study.

A great step forward understanding the origin of high energy CRA was made in recent publications (2007), connecting them with close to our galaxy, but extragalactic, black hole radiation [47].

It seems that life is optimal when the environment is at moderate activity level that prevents the mentioned factors not to achieve critical levels for human health. It's especially important for the sick and elderly population.

100 years after A. Tchizhevsky formulated the possibilities of Solar influences on human life [48], Clinical Cosmobiology, using the achievements of Space exploration and data computerization presents new data for understanding the nature of physical environment effects on human life and death-a part of life. Here we can quote A. Einstein words "The Human will is free only in bounds of a determined cosmic system" [49].

\section{CONCLUSION}

Solar and Cosmic Ray (Neutron) activity remain significantly connected with monthly deaths distribution in the last two decades.

The role of Stroke related deaths is rising. Prevention and treatment deserve more attention.

Geomagnetic activity, remarkable at daily account at extreme levels is less important in monthly studies because rare high level activity occurrence.

Gender differences are seen. In woman seasonality of death is more expressed than in men.

The clarification of the mechanisms of action of cosmophysical factors on humans and biological objects deserve additional studies.

The presented data support the view that the optimal situation for human health is concomitant with moderate levels of antagonistic environmental physical forces.

\section{REFERENCES}

[1] National Oceanic and Atmospheric Administration, SWPC-USAF preliminary report and forecast of solar geophysical data, weekly. http://www.SWPC.

[2] NOAA, National Geophysical Data Center, Solar Indices Bulletin.

[3] NOAA, National Geophysical Data Center, Geomagnetic Indices Bulletin.

[4] NOAA-USAF, "SESC glossary of solar-terrestrial terms," Boulder, USA, 1988 (revised 1992), pp. 1-69.

[5] Russian Academy of Sciences, Izmiran Institute, Cosmic data, monthly.

[6] Russian Academy of Sciences, Moscow Neutron Monitoring Station, Daily, monthly, yearly neutron monitoring data.

[7] Neutron monitoring data. Oulu University.

[8] Stoupel, E. (1976) Forecasting in cardiology. J. Wiley \& Sons, New York.

[9] Halberg, F., Cornelissen, G., Chen, C.H., Katinas, C.S., Watanabe, Y., Otsuka, K., Herold, M., Loeckinger, A., Kreze, E., Perfetto, F., Tarquini, R., Maggioni, C. and Schwartzkopff, O. (2000) Chronobiology: The time structures, chronomes gauge, aging, diseases risk and the cosmos. Journal of Anti-Aging Medicine, 3, 67-90. doi:10.1089/rej.1.2000.3.67

[10] Oraevskij, V.N., Breus, T.K., Baevskij, B.M., Rapoport, S.I., Petrov, V.M. and Barsukova, Zh. V., (1998) Effect of geomagnetic activity on the functional status of the body. Biophisika, 43, 819-826.

[11] Stoupel, E. and Shimshoni, M. (1991) Hospital cardiovascular deaths and total distribution of deaths in 180 consecutive months with different cosmic physical activity: A correlative study (1974-1988). International Journal of Biometeorology, 35, 6-9. doi:10.1007/BF01040956

[12] Nuzhdina, M.A. (1998) Effect of natural factors on the occurrence of cardiovascular diseases. Biofizika, 43, 640646.

[13] Stoupel, E. (2002) The equilibrium paradigm in clinical cosmobiology. Journal of Basic and Clinical Physiology and Pharmacology, 13, 255-261. doi:10.1515/JBCPP.2002.13.3.255 
[14] Stoupel, E. (2002) The effect of geomagnetic activity on cardiovascular parameters. Biomed Pharmacother, 56, 247s-256s. doi:10.1016/S0753-3322(02)00299-8

[15] Stoupel, E., Babayev, E., Mustafa, F., Abramson, E., Israelevich, P. and Sulkes, J. (2006) Clinical cosmobiology - sudden cardiac death and daily/monthly geomagnetic, cosmic ray, and solar activity-the Baku study, 2003-2005. Sun \& Geosphere, 1, 13-16.

[16] Beaglerole, R. (2010) International trends in coronary heart disease mortality, morbidity, risk factors. Oxford Journals Medicine. Epidemiologic Review, 12, 1-15.

[17] Stoupel, E. (2006) Cardiac arrhythmia \& geomagnetic activity. Indian Pacing \& Electrophysiology Journal, 6, 49-53.

[18] Stoupel, E., Domarkiene, S., Radishauskas, R., Abramson, E., Israelevich, P. and Sulkes, J. (2006) Neutrons \& sudden cardiac death (SCD) codes 121-125. ICD 10. Journal of Basic and Clinical Physiology and Pharmacology, 17, 45-54 doi:10.1515/JBCPP.2006.17.1.45

[19] Stoupel, E., Kusniec, J., Mazur, A., Zabarsky, R., Golovchiner, G., Abramson, E., Sulkes, J., Strasberg, B. and Battler, A. (2006) Are neutrons involved in the pathogenesis of life threatening arrhythmias? Journal of Basic and Clinical Physiology and Pharmacology, 17, 55-62. doi:10.1515/JBCPP.2006.17.1.55

[20] Stoupel, E., Kusniec, J., Mazur, A., Abramson, E., Israelevich, P. and Strasberg, B. (2008) Timing of lifethreatening arrhythmias detected by implatable cadioverter-defibrillators in relation to changes in cosmophysical factors. Cardiology Journal, 15, 1-4

[21] Stoupel, E., Assali, A., Teplitzky, I., Israelevich, P., Abramson, E., Sulkes, J., Kornowski, R. (2008) The culprit artery in acute myocardial infarction in different environmental physical activity levels. International Journal of Cardiology, 126, 288-290. doi: 10.1016/j.ijcard.2007.05.050

[22] Stoupel, E., Joshua, H. and Lahav, J. (1996) Human blood coagulation and geomagnetic activity. European Journal of Internal Medicine, 7, 217-220.

[23] Stoupel, E., Abramson, E., Israelevich, P., Sulkes, J. and Harell, D. (2007) Dynamics of C-reactive protein (CRP)environmental links. European Journal of Internal Medicine, 18, 124-128.

doi: 10.1016/j.ejim.2006.09.010

[24] Stoupel, E., Domarkiene, S., Radishauskas, R. and Abramson, E. (2003) Deaths from ischemic and hemorrhagic stroke on days of different levels of geomagnetic activity. Seminars of Cardiology, 9, 46-51.

[25] Gurfinkel, Y.I., Liubimov, V.V., Orjevskij, V.N., Parfenova, L.M. and Yurjev, A.S. The influence of geomagnetic disturbances on capillary flow in ischemic heart disease patients. Biofizika, 40, 793-799.

[26] Stoupel, E., Kalediene, R., Petrauskiene, J., Israelevich, P., Abramson, E. and Sulkes, J. (2003) Temporal distribution of death among oncology patients: Environmental links. Journal of Basic and Clinical Physiology and Pharmacology, 14, 225-233. doi:10.1515/JBCPP.2003.14.3.225

[27] Breus, T.K., Ozheredov, V.A., Siutkina, E.V. and Rogoza, A.N. (2008) Some aspects of the biological effects of space weather. Atmospheric \& Solar-Terrestrial Physics, 70, 436-441.

doi:10.1016/j.jastp.2007.08.025

[28] Stoupel, E. (1980) Solar-terrestrial predictions-aspects for preventive medicine. In: Donnelly, R.F., Ed., SolarTerrestrial Prediction Proceedings, National Oceanic Atmospheric Administration, Environmental Research Laboratories, Boulder.

[29] Bernotiene, G., Radishauskas, R., Gogelis, G., Bernotaite, L. (2006) Coincidence of mortality from ischemic heart disease registry and official mortality statistics in kaunas middle-aged population. Lithuanian Family Physician, 10, 320-324.

[30] Stoupel, E., Kalediene, R., Petrauskiene, J., Starkuviene, S., Abramson, E., Israelevich, P. and Sulkes, J. (2005) Suicide-Homicide Temporal Interrelationship, Links with other fatalities, and environmental physical activity. Crisis, 26, 85-89. doi:10.1027/0227-5910.26.2.85

[31] Stoupel, E., Kalediene, R., Petrauskiene, J., Gaiz'auskiene, A., Israelevich, P., Abramson, E. and Sulkes, J. (2007) Clinical cosmobiology: Distribution of deaths during 180 months and cosmophysical activity. The lithuanian study, 1990-2004. The role of cosmic rays. Medicina, 42, 238241.

[32] Stoupel, E., Babayev, E., Mustafa, F., Abramson, E., Israelevich, P. and Sulkes, J. (2007) Acute myocardial infarction occurrence: Environmental links-baku, 20032005. Medical Science Monitor, 13, 175-179.

[33] Stoupel, E., Domarkiene, S., Radishauskas, R., Bernotiene, G., Abramson, E., Israelevich, P. and Sulkes, J. (2004) Links between monthly rates of four subtypes of acute myocardial infarction and their corresponding cosmophysical activity parameters. Journal of Basic and Clinical Physiology and Pharmacology, 15, 175-184. doi:10.1515/JBCPP.2004.15.3-4.175

[34] Sigl, G. (2001) Ultra-high energy cosmic rays: Physics and astrophysics at extreme energies. Science, 291, 73-79. doi:10.1126/science.291.5501.73

[35] Amelino, C.G. (2002) Relativity: Special treatment. Nature, 418, 34-35. doi:10.1038/418034a

[36] Cho. A. (2007) Enormous detector forces rethink of highest energy cosmic rays. Science, 317, 178-179. doi:10.1126/science.317.5835.178

[37] Dorfman, L.I. (2003) Cosmic rays and space weather israel cosmic ray center and emilio serge observatory. Israel, IZMIRAN; Russian Academy of Sciences, Russia.

[38] McKee, M. and Shkolnikov, V. (2001) Understanding the tollof premature death among men in eastern Europe. British Medical Journal, 323, 1051-1055. doi:10.1136/bmj.323.7320.1051

[39] Stankuniene, V. Demographic development of Lithuania: Trends and impacts. VASAB Expert Band Stakeholder Meeting on Demographic Trends and Labor Market Development, 8 June 2010, Lithuania Press, Kaunas, 1-14.

[40] Stoupel, E. (2008) Atherothrombosis: Environmental links. Journal of Basic and Clinical Physiology and Pharmacology, 19, 37-45. doi:10.1515/JBCPP.2008.19.1.37

[41] Stoupel E. Atherothrombosis: Environmental Links. (2008) Journal of Basic and Clinical Physiology and Pharmacology, 19, 37-45. 
doi:10.1515/JBCPP.2008.19.1.37

[42] Nias, A.H.W. (1999) An introduction to radiobiology. J. Wiley \& Sons, New York.

[43] Hall, E.J. and Giaccia, A.J. (2006) Radiobiology for the radiologists. 6th Edition, Lippincott, Williams\& Wilkins, Philadelphia, Baltimore, New York, London, Buenos Aires, Hong Kong, Sydney, Tokyo.

[44] Kirbi, A.J. and Hollfelder, F. (1995) Enzymes under the nanoscope nature 2008, 456; 6: 45-44. Stoupel E, Abramson E, Gabbay U, Pick AI Relationship between immunoglobulin levels and extremes of solar activity. Int J Biometeorol 38: 89-9.

[45] Stoupel, E., Monselize, Y., Lahav, J. (2006) Changes in autoimmune markers of the anti cardiolipin syndrome on days of extreme geomagnetic activity. Journal of Basic and Clinical Physiology and Pharmacology, 17, 269- 278.

doi:10.1515/JBCPP.2006.17.4.269

[46] Stoupel, E., Petrauskiene, J., Gabbay, U., Kalediene, R., Abramson, E. and Sulkes, J. (2001) Circannual rhythmicity of deaths distribution. Acta Medica Lithuanica, 6, 37-42.

[47] The Pierre Auger Collaboration. (2007) Correlation of the highest-energy cosmic rays with nearly extragalactic objects. Science, 318, 938-943.

doi:10.1126/science.1151124

[48] Tchizhevsky, A. (1936) Terrestrial echo's of solar storms. Nauka, Moscow.

[49] Einstein, A. (1932) Mein weltbild. 